\title{
PLUMAGE MICRO-ORGANISMS AND PREEN GLAND SIZE IN AN URBANIZING CONTEXT
}

\section{GIRAUDEAU, MATHIEU ${ }^{1,2}$, STIKELEATHER, RYAN ${ }^{1}$, McKENNA, JENNIFER ${ }^{1}$, HUTTON, PIERCE ${ }^{1}$ AND McGRAW, KEVIN J. ${ }^{1}$}

${ }^{1}$ Arizona State University, School of Life Sciences, Tempe, AZ 85287-4501, USA.

${ }^{2}$ Centre for Ecology and Conservation, College of Life and Environmental Sciences, University of Exeter, Penryn, UK

*Correspondence author. E-mail: giraudeau.mathieu@gmail.com, Tel : (480) 727-9094, fax: (480) 965-6899

Running title: Feather-degrading bacteria and preen gland size in urban and rural birds

18 pages

3689 words

2 figures, 1 table 


\begin{abstract}
Urbanization of Earth's habitats has led to considerable loss of biodiversity, but the driving ecological mechanism(s) are not always clear. Vertebrates like birds typically experience urban alterations to diet, habitat availability, and levels of predation or competition, but may also be exposed to greater or more pathogenic communities of microbes. Birds have been popular subjects of urban ecological research but, to our knowledge, no study has assessed how urban conditions influence the microbial communities on bird plumage. Birds carry a large variety of microorganisms on their plumage and some of them have the capacity to degrade feather keratin and alter plumage integrity. To limit the negative effects of these feather-degrading bacteria, birds coat their feathers with preen gland secretions containing antibacterial substances. Here we examined urban-rural variation in feather microbial abundance and preen gland size in house finches (Haemorhous mexicanus). We found that, although urban and rural finches carry similar total-cultivable microbial loads on their plumage, the abundance of feather-degrading bacteria was on average three times higher on the plumage of urban birds. We also found an increase in preen gland size along the gradient of urbanization, suggesting that urban birds may coat their feathers with more preen oil to limit the growth or activity of feather-degrading microbes. Given that greater investment in preening is traded-off against other immunological defenses and that feather-degrading bacteria can alter key processes like thermoregulation, aerodynamics, and coloration, our findings highlight the importance of plumage microbes and microbial defenses on the ecology of urban birds.
\end{abstract}

Keywords: feather microbes, Haemorhous mexicanus, uropygial gland, urbanization 


\section{INTRODUCTION}

Urbanization continues to threaten natural landscapes and maintenance of biodiversity worldwide (Aronson et al. 2014). Species richness declines from rural areas toward urban centers in several taxonomic groups, including birds, mammals, and insects (Marzluff 2001, McKinney 2008). Over the last decade, there has been a scientific push to understand the mechanisms behind this process and, due to their broad life-history effects on their hosts, parasites have been proposed as one of the reasons explaining urban loss of vertebrate and invertebrate biodiversity (Bradley and Altizer 2007). In line with this hypothesis, recent studies have shown increased parasite loads in urban compared to rural animal populations (Giraudeau et al. 2014a, Becker et al. 2015), a pattern that may be due to urban shifts in parasite transmission/virulence or in host susceptibility (e.g. condition and immunocompetence; Audet et al. 2015, Martin et al. 2010).

Typically, urban studies of animal parasites have centered on endogenous pathogens, and less emphasis has been placed on aspects of environmental transmission of microbes. Birds offer an interesting urban microbiological study system, due to the fact that they carry a large variety of microorganisms on their plumage and some of them, the feather-degrading bacteria, have the capacity to alter plumage integrity through their ability to degrade $\beta$-keratin, a protein which composes more than $90 \%$ of feather mass (Onifade et al. 1998, Burtt and Ichida 1999, Gunderson 2008). Feather damage caused by these feather-degrading bacteria can alter the plumage insulative efficiency, causing thermoregulatory stress, or reduce aerodynamic efficiency (Clayton, 1999) and plumage coloration (Shawkey et al. 2007, 2008, Gunderson et al. 2009, Leclaire et al. 2014). To limit the negative effects of feather bacteria, birds have evolved several lines of defenses, including sun and dustbathing, specialized feather structure, seasonal/annual feather molt, or preening behavior (Gunderson 2008). The preen gland is present in nearly every bird species and the secretions produced by this gland are coated on feathers during preening 
sequences. Preen oil contains antibacterial substances that have been shown to inhibit the growth of feather-degrading and non-feather-degrading bacteria (Shawkey et al. 2003). These observations raise the questions of whether urban birds may harbor greater plumage microbial communities and whether such ecological conditions may shape their investment in the preen gland or preening behavior.

Surprisingly, no studies to date have examined if or how feather-degrading bacterial loads vary in urban vs. rural birds and how urban birds might respond to increased exposure to these pathogenic bacteria (i.e., investment in preen gland or preening). Recently, Chatelain et al. (2015) have shown that an experimental exposure to trace metals (pollutants emitted by anthropogenic activities) led to modifications of plumage bacterial load, bacterial community composition and preening behavior; suggesting that urban conditions might influence plumage micro-organisms and their hosts.

Here, we compared total and feather-degrading cultivable microbial loads in urban and rural house finches (Haemorhous mexicanus). Moreover, we captured 830 house finches from 8 sites along an urban-rural gradient over a period of 9 months to assess if and how preen gland size (a proxy for plumage protection from microbes; Martin-Vivaldi et al. 2009) varies as a function of habitat urbanization.

\section{METHODS}

\section{Preen gland size}

Birds were captured at each of 8 study sites along a gradient of urbanization (see Giraudeau et al. 2014a,b for a detailed description of the sites) from January-September 2011 using basket and Potter traps baited with sunflower seeds ( $=830$, all males); trapping sessions lasted from 0700- 
1200 hrs. At capture, each bird was leg banded with a numbered United States Geological Survey metal tag for individual identification. We also determined tarsus length (to the nearest $0.1 \mathrm{~mm}$ ) and preen gland size (length and width, to the nearest $0.01 \mathrm{~mm}$; Jacob et al. 2014). Afterwards, we used preen gland length and width to estimate an elliptical area $\left(\mathrm{mm}^{2}\right.$; Galvan and Sanz 2006).

\section{Plumage bacterial load}

Nine urban males and eight rural males were captured in July 2014 at each of 2 urban and 2 desert study sites (rural: Estrella Mountain Park and South Mountain Reserve, urban: Phoenix downtown and the Arizona State University campus). We selected this subset of sites because they comprise the most rural- and urban-like of our original 8 sites and therefore capture the full range of environmental variation due to human activities (Hasegawa et al. 2014). At capture, the crown, breast, back, belly, and rump feathers of each bird were swabbed with a sterile cotton tipped applicator (Puritan medical products) to collect the plumage microbiota. Plumage bacteria can be distinguished into two ecological types (free-living and attached, Alt et al. 2015) and only free-living bacteria have been collected with this method. The swabs were then kept in sterile $1.5 \mathrm{ml}$ screw-cap microtubes containing $0.5 \mathrm{ml}$ of tryptic soy broth with $20 \%$ glycerol and bacterial load was measured within 2 hours after sample collection.

To separately quantify total-cultivable and feather-degrading bacterial loads, we used two different growth media (Giraudeau et al. 2010, 2013, Czirjak et al. 2013). Firstly, Trypticase Soy Agar (TSA, \#22091, Fluka) is a rich medium on which many heterotrophic bacteria grow, thus

enabling assessment of the total cultivable microbe loads on the feathers. Secondly, we quantified the feather-degrading bacterial load using Feather Meal Agar (FMA) media (Sangali 
and Brandelli 2000, Shawkey et al. 2003, 2007, Møller et al. 2009). One hundred microliters of the microbial solution were spread on each of the two growth media and the plates were incubated at $37^{\circ} \mathrm{C}$, for $48 \mathrm{hrs}$ in the case of TSA, and for $72 \mathrm{hrs}$ for the FMA. After incubation, the numbers of visible colony-forming units (CFU) on each plate were counted. All counts were performed by one of us (RS) without knowledge of bird origin.

\section{Metrics of urbanization}

Following Giraudeau et al. (2014b), we extracted eight urbanization parameters from a local database that is part of the Central Arizona-Phoenix Long-Term Ecological Research program: (1) human population density within a radius of $1 \mathrm{~km}$ around each trapping site, estimated from the 2010 US Census data; (2) land-use and land-cover (LULC, in 2007) variables within the same $1 \mathrm{~km}$ radius. From satellite images, we determined percentage of land dedicated to 7 land uses: cultivated vegetation and cultivated grass, river gravel and water, vegetation, disturbedcommercial/industrial and asphalt, undisturbed, disturbed-compacted soil, disturbed-mesic and xeric vegetation residential. We then generated urbanization scores using PCA for the eight variables cited above. PC1 loaded strongly and negatively with the amount of undisturbed land cover, and strongly and positively with the amount of disturbance caused by yards and industry. PC2 was loaded strongly and positively with both the amount of compacted soil and vegetation (Giraudeau et al. 2014b. see ESM).

\section{Statistics}

Statistics were completed in the R statistical computing environment (R Core Team, 2014) with $\alpha$ set to 0.05 . To test for urban and seasonal variation in preen gland size (Spring: March - May, 
Summer: June - August, Fall: September - November, Winter: December - February), we created linear models initially loaded with habitat PC1, habitat PC2, season, and the two-way interactions of season with both habitat PCs. Preen gland elliptical area was not significantly related to tarsus length (a good indicator of skeletal size in passerines; Senar and Pascual, 1997), meaning that larger birds did not have larger preen glands $(\beta=-0.10, \mathrm{p}=0.20)$. We thus used uncorrected values of preen gland elliptical area. Non-significant interactions $(p>0.05)$ were sequentially removed from the initial models (Zuur et al. 2009) to eventually provide a final model. Non-significant lower-order effects were not removed if they were contained in a significant higher-order interaction (Zuur et al. 2009). We used multiple imputation to recover a single missing value, which was determined to be missing at random, in the bacterial load data set with the mice package in $\mathrm{R}$ and combined all imputed datasets for further analyses (Little and Rubin 2002). We chose this method because only a single datum was missing, and alternatives such as mean replacement and serial deletion are thought to skew and bias variances (Little and Rubin 2002).

\section{RESULTS}

We found a significant positive relationship between uropygial gland size and urban PC1 (but not urban PC2; Table 1; Figure 1; PC1 standardized $\beta=0.084$ ). Uropygial gland size varied across seasons as well, with it being larger during spring and summer compared to fall and winter (Table 1).

Urban and rural birds did not differ in the abundance of total cultivable plumage bacteria (TSA media, $t$-test: $t=-0.08, \mathrm{df}=15, \mathrm{p}=0.93$; Figure 2a). However, we did find that feathers of urban finches harbored a far greater abundance of feather-degrading bacteria than rural birds 
(FMA media, Welch's Two-sample $t$-test: $t=-2.36, \mathrm{df}=8.8, \mathrm{p}=0.043$, power $=0.49$, Hedge's $g$ $=-1.02$; Figure 2a). Additionally, we found that the ratio of feather-degrading bacteria to totalcultivable bacteria was significantly different between populations, with urban birds having proportionally more feather-degrading bacteria per total-cultivable bacteria (Mann-Whitney U test: $\mathrm{U}=53, \mathrm{p}=0.028$, Hedge's $g=0.93$; Figure 2b).

\section{DISCUSSION}

Here we show that urban and desert birds carry similar total-cultivable bacteria loads on their plumage but that the abundance of feather-degrading bacteria was on average three times higher on the plumage of urban birds. This result is consistent with a previous study from our group, in which we found that the prevalence and severity of infection by a gut protozoan (coccidians from the genus Isospora) and a virus (genus Poxvirus) increased along the same gradient of urbanization in house finches (Giraudeau et al. 2014a). More generally, this result adds to the growing literature showing increased parasite loads in urban habitats (Bradley et al. 2008, Lehrer et al. 2010, Goulson et al. 2012, Kellner et al. 2012).

Microorganisms compete with each other for space and resources and can optimally thrive under particular environmental conditions, but surprisingly little is known about the competition and colonization efficacy of feather-degrading bacteria relative to other bacteria. Our results suggest that urban conditions are favorable for feather-degrading bacteria in finches. Another hypothesis to explain our result would be that the higher densities of birds in cities and the increased contact rate between birds would favor the transmission of plumage bacteria. In line with this hypothesis, Møller et al. (2009) found that the abundance of feather-degrading bacteria was positively related to colony size in barn swallows (Hirundo rustica). While we 
cannot rule out the idea that feather-degrading bacteria might have a higher transmission rate than commensal bacteria, a higher transmission of plumage bacteria in dense populations (urban populations in our case) seems unlikely given that no difference in total-cultivable bacterial loads have been found in both studies.

We also found an increase in preen gland size along the gradient of urbanization, suggesting that, under the assumption that larger glands produce more oil (Galvan et al. 2008) urban finches have the ability to coat their feathers with more preen oil to combat the comparatively more abundant feather-degrading bacterial community. An increase of preen gland size has been recently measured in response to an experimental increase of plumage bacteria density in great tits (Parus major, Jacob et al. 2014). Similarly, an experimental reduction of the feather bacteria load in feral pigeons (Columbia livia) led to a decreased investment in preen oil secretions and in preening behavior (Leclaire et al. 2014). Taken together, these results show that preen gland size and putative oil production is a plastic trait that can be adjusted according to the bacterial community present on the plumage. However, investment in this antimicrobial defense seems to be traded-off against components of the immune system (Leclaire et al. 2015), possibly influencing the host resistance to others parasites and the evolution of the avian host-pathogen interactions.

Despite their increased investment in antimicrobial defenses, urban birds still carried three times more feather-degrading bacteria than rural birds, and this has potentially large fitness consequences, in terms of reduced thermoregulation, aerodynamics, and plumage coloration. To our knowledge, no studies have ever compared plumage quality (proportion of damaged vs. undamaged barbs, Shawkey et al. 2007) between urban and rural birds, but an increased and faster feather degradation caused by feather-degrading bacteria might be an important 
component explaining the decreased coloration recurrently found in urban birds (Hõrak et al. 2000, Isaksson et al. 2005, Giraudeau et al. 2015, Hutton and McGraw 2016). Most of the plumage colors that have been studied in urban ecological contexts result from the combination of a keratin-based background structure that reflects light and pigments that absorb light (Jacot et al. 2010). Thus, degradations of the feather keratin structure by bacteria might influence a large suite of color-producing mechanisms in urban bird plumage (Shawkey et al. 2007) and thus strongly influence the inter- and intra-sexual interactions in the urban environment.

To conclude, we have shown for the first time that urban house finches carried more feather-degrading bacteria and had larger preen glands than rural finches. Given that greater investment in preening can be traded-off against immunological investments (Leclaire et al. 2015) and that feather-degrading bacteria can alter key fitness traits like aerodynamics and coloration (via effects on plumage integrity; Gunderson et al. 2009), our findings highlight the potential functional importance of plumage microbes and microbial defenses on the ecology of urban birds.

\section{Acknowledgements}

This material is based upon work supported by the National Science Foundation under grant number DEB-1026865, Central Arizona-Phoenix Long-Term Ecological Research (CAP LTER). We thank Estrella and South Mountain Regional Parks and the Lundgren's for permitting access to finch study sites.

Ethical approval: All applicable institutional and/or national guidelines for the care and use of animals were followed 


\section{REFERENCES}

Alt, G., Saag, P., Mägi, M., Kisand, V., Mänd, R., 2015. Manipulation of parental effort affects plumage bacterial load in a wild passerine. Oecologia 178, 451-459.

Aronson, M.F., La Sorte, F.A., Nilon, C.H., Katti, M., Goddard, M.A., Lepczyk, C.A., Warren, P.S., Williams, N.S., Cilliers, S., Clarkson, B., Dobbs, C., 2014. A global analysis of the impacts of urbanization on bird and plant diversity reveals key anthropogenic drivers. Proc R Soc B 281, 20133330.

Audet, J.N., Ducatez, S., Lefebvre, L., 2015. The town bird and the country bird: problem solving and immunocompetence vary with urbanization. Behav. Ecol. arv201.

Becker, D.J., Streicker, D.G., Altizer, S., 2015. Linking anthropogenic resources to wildlifepathogen dynamics: a review and meta-analysis. Ecol. Letters 18, 483-495.

Bradley, C.A., Altizer, S. 2007. Urbanization and the ecology of wildlife diseases. Trends ecol. evol. 22, 95-102.

Bradley, C.A., Gibbs, S.E., Altizer, S., 2008. Urban land use predicts West Nile virus exposure in songbirds. Ecol. Appl. 18, 1083-1092.

Burtt, E.H. Jr., Ichida, J.M., 1999. Occurrence of feather degrading bacilli in the plumage of birds. Auk 116, 364-372.

Clayton, D.H., 1999. Feather busting bacteria. Auk 116, 302-304.

Czirják, G.Á., Pap, P.L., Vágási, C.I., Giraudeau, M., Mureşan, C., Mirleau, P., Heeb, P., 2013. Preen gland removal increases plumage bacterial load but not that of feather-degrading bacteria. Naturwissenschaften 100, 45-151.

Galvan, I., Sanz, J.J., 2006. Feather mite abundance increases with uropygial gland size and plumage yellowness in great tits Parus major. Ibis 148, 687-697. 
Galván, I., Barba, E., Piculo, R., Cantó, J.L., Cortés, V., Monrós, J.S., Atiénzar, F., Proctor, H., 2008. Feather mites and birds: an interaction mediated by uropygial gland size? J. Evol. Biol. 21, 133-144.

Giraudeau, M., Czirják, G.Á., Duval, C., Guiterrez, C., Bretagnolle, V., Heeb, P., 2010. No detected effect of moult on feather bacterial loads in mallards Anas platyrhynchos. J. Avian Biol. 41, 678-680.

Giraudeau, M., Czirják, G.Á., Duval, C., Bretagnolle, V., Gutierrez, C., Guillon, N., Heeb, P., 2013. Effect of preen oil on plumage bacteria: an experimental test with the mallard. Behav. Process 92, 1-5.

Giraudeau, M., Mousel, M., Earl, S., McGraw, K., 2014a. Parasites in the city: degree of urbanization predicts poxvirus and coccidian infections in house finches (Haemorhous mexicanus). PLoS One 9, e86747.

Giraudeau, M., Nolan, P.M., Black, C.E., Earl, S.R., Hasegawa, M., McGraw, K.J. 2014b. Song characteristics track bill morphology along a gradient of urbanization in house finches (Haemorhous mexicanus). Frontiers in zoology 11, 1.

Giraudeau, M., Chavez, A., Toomey, M.B., McGraw, K.J., 2015. Effects of carotenoid supplementation and oxidative challenges on physiological parameters and carotenoidbased coloration in an urbanization context. Behav. Ecol. Sociobiol. 69, 957-970.

Goulson, D., Whitehorn, P., Fowley, M., 2012. Influence of urbanisation on the prevalence of protozoan parasites of bumblebees. Ecol. Entomol. 37, 83-89.

Gunderson, A.R., 2008. Feather-degrading bacteria: a new frontier in avian and host-parasite research. Auk 125, 1-8.

Gunderson, A.R., Forsyth, M.H., Swaddle, J.P., 2009. Evidence that plumage bacteria influence 
feather coloration and body condition of eastern bluebirds Sialia sialis. J. Avian Biol. 40, 440-447.

Hasegawa, M., Ligon, R.A., Giraudeau, M., Watanabe, M., McGraw, K.J., 2014. Urban and colorful male house finches are less aggressive. Behav. Ecol. 25, 641-649.

Hõrak, P., Vellau, H., Ots, I., Møller, A.P., 2000. Growth conditions affect carotenoid-based plumage coloration of great tit nestlings. Naturwiss. 87, 460-464.

Hutton, P., McGraw, K.J., 2016. Urban impacts on oxidative balance and animal signals. Frontiers Ecol. Evol. 4, 54.

Isaksson, C., Örnborg, J., Stephensen, E., Andersson, S., 2005. Plasma glutathione and carotenoid coloration as potential biomarkers of environmental stress in great tits. EcoHealth 2, 138-146.

Jacob, S., Immer, A., Leclaire, S., Parthuisot, N., Ducamp, C., Espinasse, G., Heeb, P., 2014. Uropygial gland size and composition varies according to experimentally modified microbiome in Great tits. BMC Evol. Biol. 14, 1.

Jacot, A., Romero-Diaz, C., Tschirren, B., Richner, H., Fitze, P.S., 2010. Dissecting Carotenoid from Structural Components of Carotenoid-Based Coloration: A Field Experiment with Great Tits (Parus major). Am. Nat. 176, 55-62.

Kellner, K.F., Page, L.K., Downey, M., McCord, S.E., 2012. Effects of urbanization on prevalence of Baylisascaris procyonis in intermediate host populations. J. Wildl. Dis. 48, 1083-1087.

Leclaire, S., Pierret, P., Chatelain, M., Gasparini, J., 2014. Feather bacterial load affects plumage condition, iridescent color, and investment in preening in pigeons. Behav. Ecol. aru109.

Leclaire, S., Czirják, G.Á., Hammouda, A., Gasparini, J., 2015. Feather bacterial load shapes the 
trade-off between preening and immunity in pigeons. BMC Evol. Biol. 15, 1.

Lehrer, E.W., Fredebaugh, S.L., Schooley, R.L., Mateus-Pinilla, N.E., 2010. Prevalence of antibodies to Toxoplasma gondii in woodchucks across an urban-rural gradient. J. Wildl. Dis. 46, 977-980.

Little, R.J.A., Rubin, D.B., 2002. Statistical Analysis with Missing Data. Wiley, New York, USA

Martin, L.B., Hopkins, W.A., Mydlarz, L.D., Rohr, J.R., 2010. The effects of anthropogenic global changes on immune functions and disease resistance. Ann NY Acad. Sci. 1195, 129148.

Marzluff, J.M., 2001. Worldwide urbanization and its effects on birds. In Avian Ecology and Conservation in an Urbanizing World (Marzluff, J.M. et al., eds), pp. 19-38, Kluwer Academic Publishers.

McKinney, M.L., 2008. Effects of urbanization on species richness: A review of plants and animals. Urban ecosystems 11, 161-176.

Martín-Vivaldi, M., Ruiz-Rodríguez, M., José Soler, J., Manuel Peralta-Sánchez, J., Méndez, M., Valdivia, E., Martin-Platero A.M., Martínez-Bueno, M., 2009. Seasonal, sexual and developmental differences in hoopoe Upupa epops preen gland morphology and secretions: evidence for a role of bacteria. Journal of Avian Biology 40, 191-205.

Møller, A.P., Czirjak, G.A., Heeb, P., 2009. Feather microorganisms and uropygial antimicrobial defenses in a colonial passerine bird. Funct. Ecol. 23, 1097-1102.

Onifade, A.A., Al-Sane, N.A., Al-Musallam, A.A., AlZarban, S., 1998. A review: Potentials for biotechnological applications of keratin-degrading microorganisms and their enzymes for nutritional improvement of feathers and other keratins as livestock feed resources. Bioresource Technol. 66, 1-11. 
Sangali, S., Brandelli, A., 2000. Feather keratin hydrolysis by a Vibrio sp. strain kr2. J. Appl. Microbiol. 89, 735-743.

Senar, J., Pascual, J., 1997. Keel and tarsus length may provide a good predictor of avian body size. Ardea 85, 269-274.

Shawkey, M.D., Pillai, S.R., Hill, G.E., 2003. Chemical warfare? Effects of uropygial oil on feather-degrading bacteria. J. Avian Biol. 34, 345-349.

Shawkey, M.D., Pillai, S.R., Hill, G.E., 2008. Do feather degrading bacteria affect sexually selected plumage color? Naturwiss. 96, 123-128.

Shawkey, M.D., Pillai, S.R., Hill, G.E., Siefferman, L.M., Roberts, S.R., 2007. Bacteria as an agent for change in structural plumage color: correlational and experimental evidence. Am. Nat. 169, S112-S121.

Zuur, A.F., Ieno, E.N., Walker, N.J., Saveliev, A.A., Smith, G.M., 2009. Mixed Effects Models and Extensions in Ecology with R. Springer Science, New York, USA. 


\section{TABLES AND FIGURES}

Table 1. Final linear model including predictors for uropygial gland size.

\begin{tabular}{lllrr}
\hline Response & Predictor & Degrees of freedom $(\mathbf{n}, \mathbf{d})$ & F-value & P-value \\
\hline Uropygial gland area & Season & 3,824 & 9.44 & $<0.0001$ \\
& PC1 & 1,824 & 5.99 & 0.015 \\
& PC2 & 1,824 & 0.37 & 0.52 \\
& PC1*Season & - & - & NS \\
& PC2*Season - & - & NS \\
\hline
\end{tabular}


Figure 1. Urban PC1 predicts variation in preen gland. Points and whiskers represent means and standard errors of the mean for each study site.

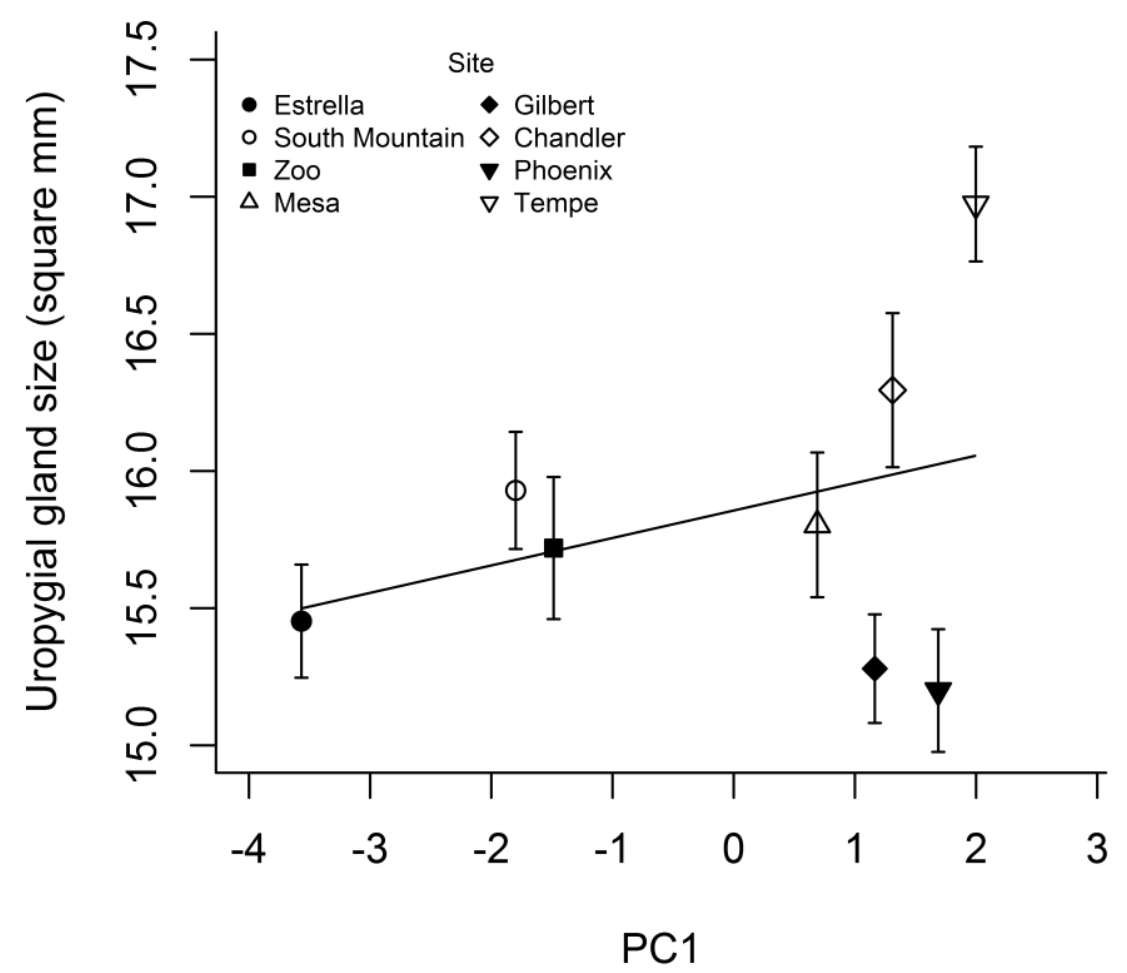


Figure 2. Urban-rural variation in plumage microbes. (a) Amounts of total-cultivable bacteria and feather-degrading bacteria in urban and rural finches. (b) Ratio of total-cultivable bacteria to feather-degrading bacteria. Bars represent means and whiskers represent standard errors significant. Asterisks denote for which comparisons there were significant differences between urban and rural finches $(\mathrm{p}<0.05)$.
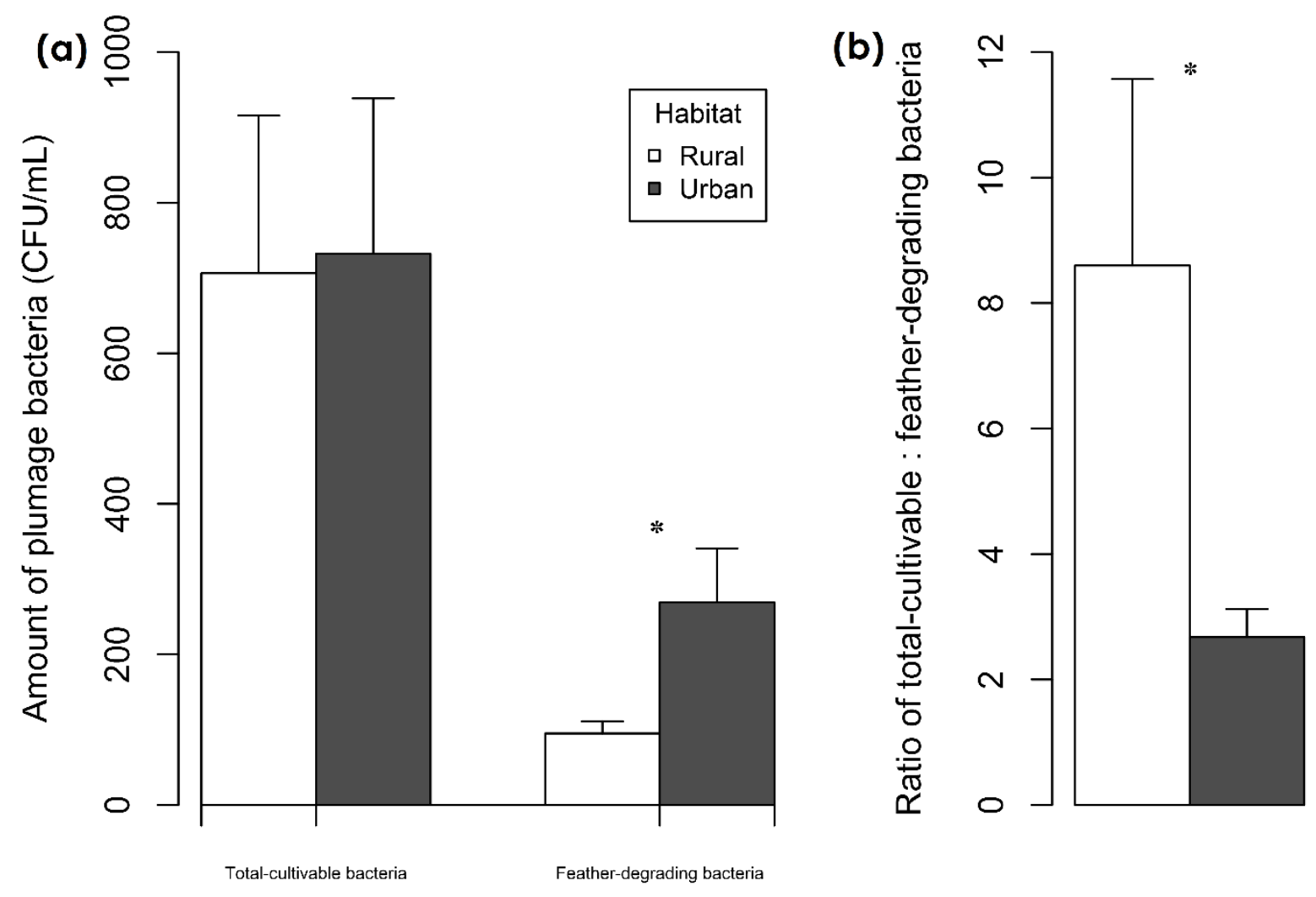

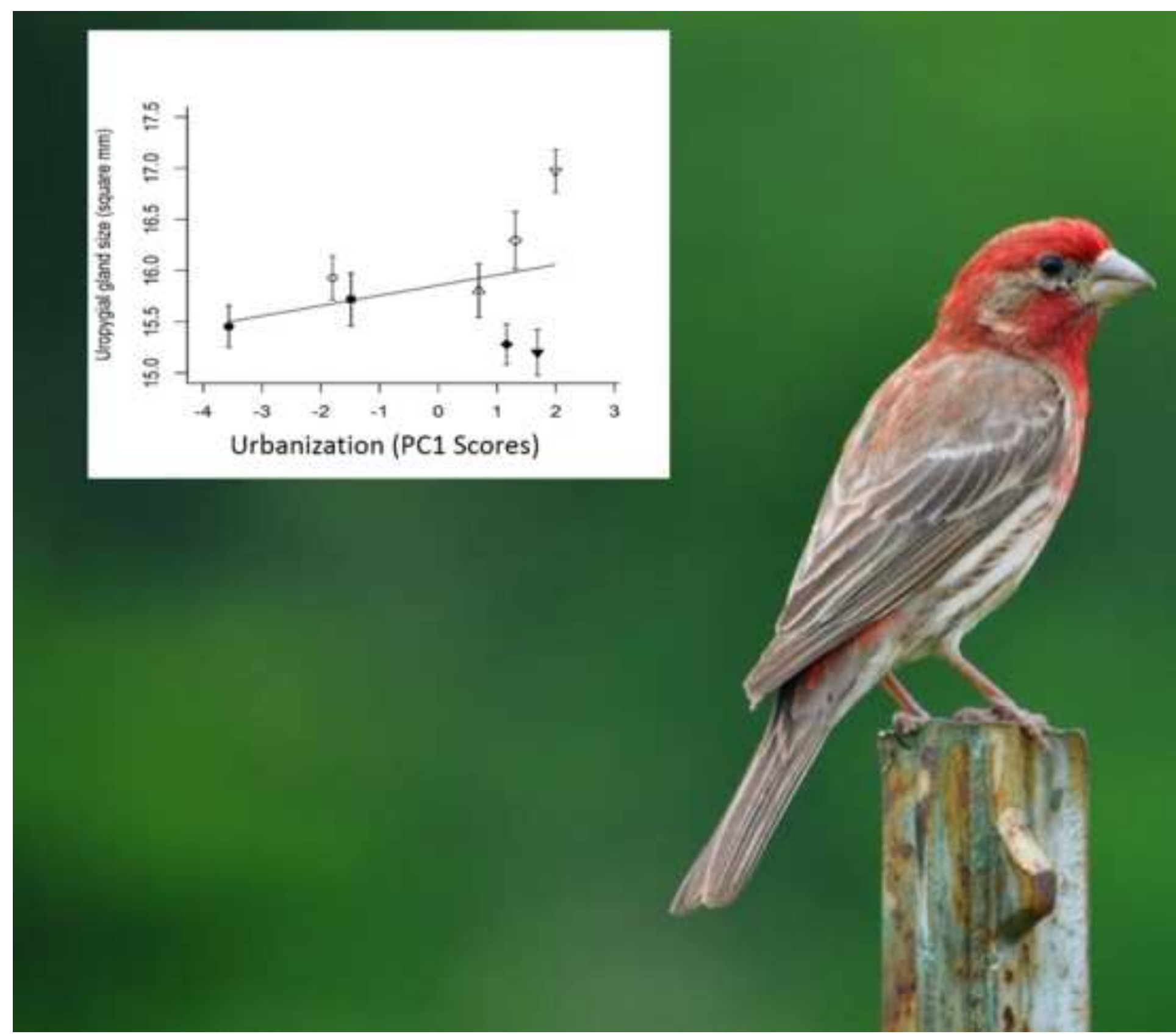